\title{
The Mabbott Collection of Medals of the French Revolution of 1848
}

\section{ALA N B. S P I T Z E R}

A superb collection of medals produced during or shortly after the French Revolution of 1848 was acquired by the late Professor Thomas Ollive Mabbott and presented to the University of Iowa Libraries in 1969 by his widow, Mrs. Thomas O. Mabbott.1 The collection consists of some 842 items, including large, elaborately designed, commemorative medallions; a wide variety of cheap medals struck, in the beat of the political conflict, from tin or lead; and numerous small pieces or "jetons" which functioned as membership cards, lapel insignia, and entrance tickets to the multitude of political clubs and reformist organizations that appeared in the wake of the revolution. (See the sampling of these medals reproduced on the back cover.)

The collection commemorates and documents the entire course of the crisis-the central event in the history of nineteenth-century France. The medals take us from the insurrection which overthrew the monarchy of King Louis-Philippe, through the months of political agitation and competition for the transfer of power culminating in the bloody class conflict of the "June Days," and finally document the rise to power of Louis-Napoleon Bonaparte, first elected president, and ultimately the assassin, of the Second French Republic.

The medals take their place along with the contemporary press, pamphlets, and wall placards as significant media of communication and political propaganda. Their messages, necessarily brief but permanently fixed in the metal, range from the simple celebration or criti-

1 Thomas Ollive Mabbott (1898-1968) was a teacher at Hunter College for over thirty years. Known as an outstanding Poe scholar, he was also a Milton specialist, a collector of fifteenth-century block prints, and a numismatist who had assembled a large collection of Greek and Roman coins as well as the French medals here described. 
cism of some salient event or political leader to complex commentaries, polemics, allegories, satires, and even cryptograms. They not only constitute a fascinating record of political attitudes but provide an invaluable documentation of contemporary culture in their representation of iconographic themes borrowed from classical antiquity, freemasonry, and the great tradition of the revolution of 1789 .

The medals depicted in the centerfold on pages 32 and 33 illustrate these themes. The silverplated medal on page 32 exemplifies the early enthusiasm and optimism following the overthrow of the monarchy in February. The spirit of liberty, torch and broken chain in hand, mounts to the heavens, flanked by the rainbow, symbol of hope. Monarchy with fallen crown and broken sceptre is struck down by a bolt from the clouds through which shines the level, a masonic emblem and symbol of equality. The reverse of this medal celebrates the insurrection of February 22, 23, and 24 and the establishment of the Second French Republic according to the revolutionary principles of Liberty, Equality, and Fraternity-heritage of the Revolution of 1789. The arms and banners of the soldiers of liberty flank the fasces, antique symbol of authority, and are surmounted by representations of the clasp of brotherhood and the masonic version of the Christian blessing.

The medal on page 33 of the centerfold is a political satire directed against Louis-Auguste Blanqui, socialist leader of the extreme Left during the revolution. The sinister skull is crowned with the Phrygian bonnet-the revolutionary's cap-and on the cap is a fleur-de-lis suggesting that revolutionary extremism is the agent of ultra-royalism. The reverse of this medal celebrates the day on which a mass demonstration led by the radicals was contained by the militia of a frightened middle class. At the bottom is the monogram of a numismatist who struck a series of anti-radical medals.

The entire collection is housed in a specially designed 24-tray coin cabinet in the Special Collections Department of the University Libraries, where also the two standard catalogs of the medals of 1848 by De Saulcy and Liesville, ${ }^{2}$ together with related publications, may be consulted.

2 [Louis Felicieu Joseph Caignart de Saulcy] Souvenirs numismatiques de la révolution de 1848 (Paris: J. Rousseau, 1848-50); A.-R. de Liesville, Histoire numismatique de la révolution de 1848 (Paris: Honoré Champion, 1877-83). 

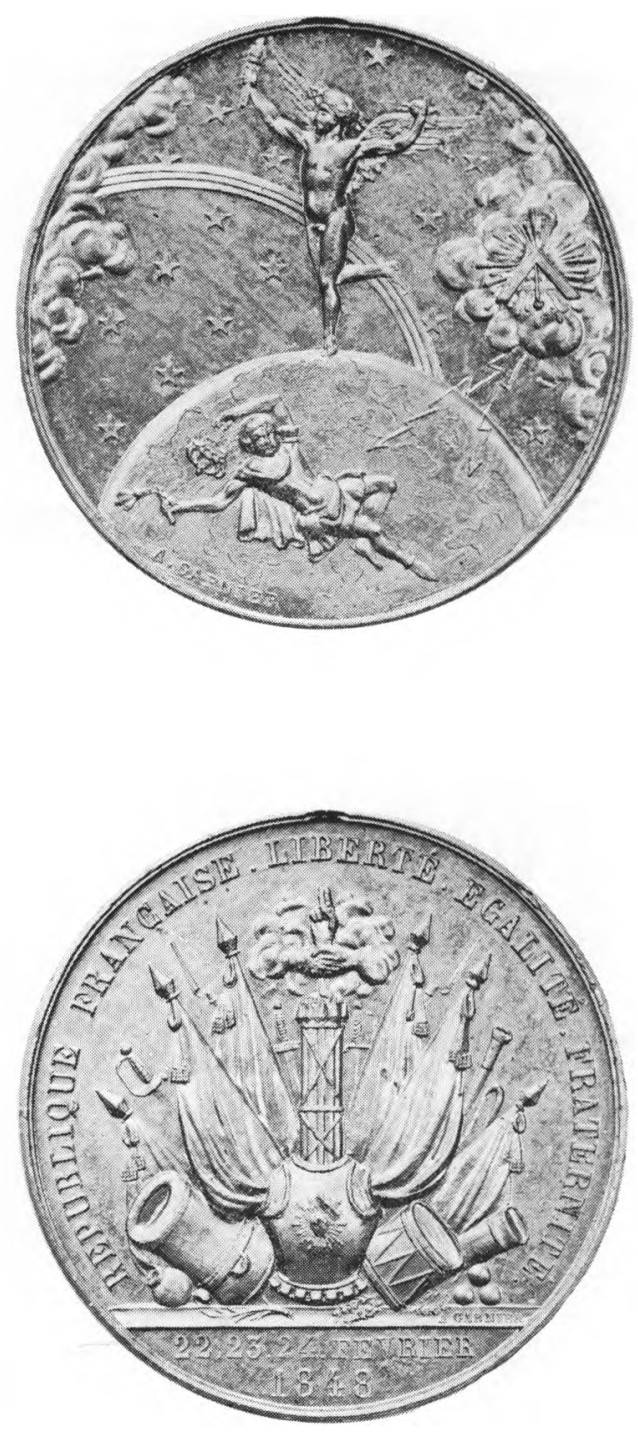

A medal celebrating the overthrow of the French monarchy in 1848. The obverse (upper) shows the spirit of liberty flanked by a rainbow, while monarchy with fallen crown and broken sceptre is struck down by a bolt from the clouds. The reverse (lower) shows the arms and banners of the soldiers of liberty. (Enlarged from $3.7 \mathrm{~cm}$.) 

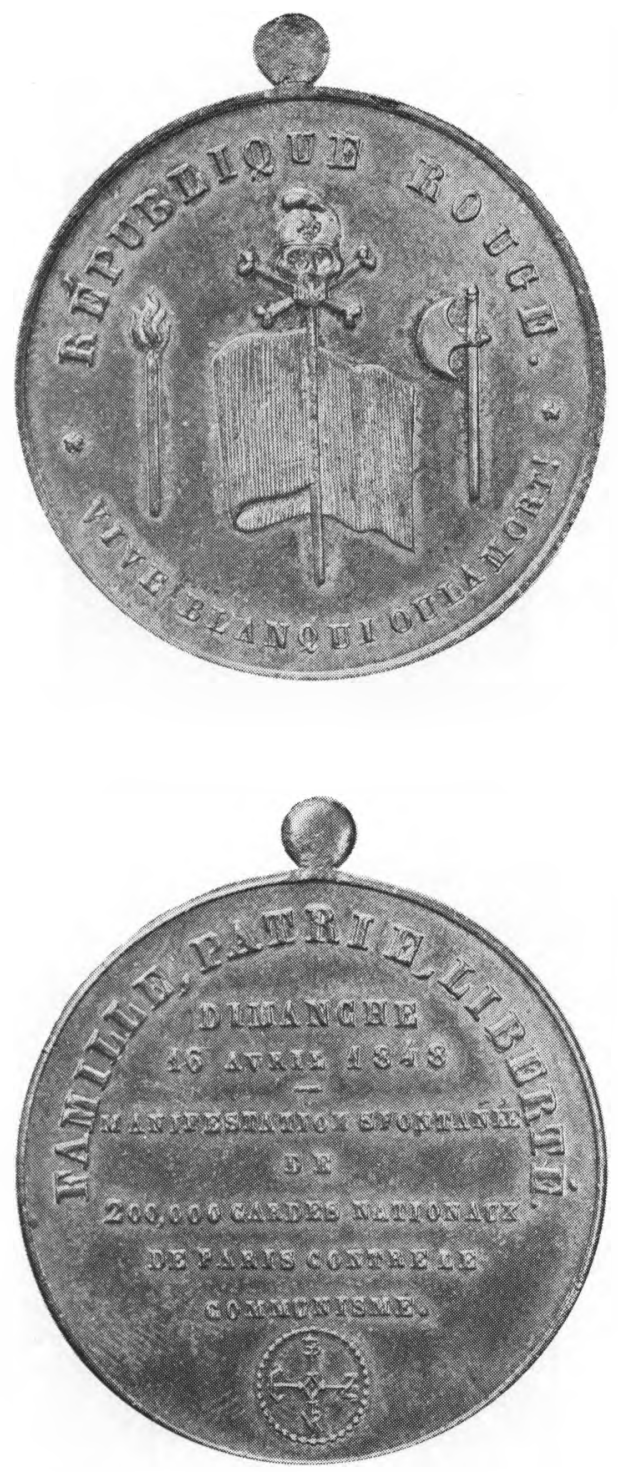

A medal satirizing Louis-Auguste Blanqui, socialist leader of the extreme Left during the revolution. The obverse (upper) shows a skull crowned with the revolutionary's cap. The reverse (lower) celebrates the day on which a mass demonstration, led by the radicals, was contained by the militia. (Enlarged from $3.7 \mathrm{~cm}$.) 